\title{
Urban air pollution and emergency room admissions for respiratory symptoms: a case- crossover study in Palermo, Italy
}

\author{
Fabio Tramuto ${ }^{1 *}$, Rosanna Cusimano ${ }^{2,3}$, Giuseppe Cerame ${ }^{1}$, Marcello Vultaggio ${ }^{4}$, Giuseppe Calamusa ${ }^{1}$, \\ Carmelo M Maida ${ }^{1}$ and Francesco Vitale
}

\begin{abstract}
Background: Air pollution from vehicular traffic has been associated with respiratory diseases. In Palermo, the largest metropolitan area in Sicily, urban air pollution is mainly addressed to traffic-related pollution because of lack of industrial settlements, and the presence of a temperate climate that contribute to the limited use of domestic heating plants. This study aimed to investigate the association between traffic-related air pollution and emergency room admissions for acute respiratory symptoms.
\end{abstract}

Methods: From January 2004 through December 2007, air pollutant concentrations and emergency room visits were collected for a case-crossover study conducted in Palermo, Sicily. Risk estimates of short-term exposures to particulate matter and gaseous ambient pollutants including carbon monoxide, nitrogen dioxide, and sulfur dioxide were calculated by using a conditional logistic regression analysis.

Results: Emergency departments provided data on 48,519 visits for respiratory symptoms. Adjusted case-crossover analyses revealed stronger effects in the warm season for the most part of the pollutants considered, with a positive association for $\mathrm{PM}_{10}$ (odds ratio $=1.039,95 \%$ confidence interval: $\left.1.020-1.059\right), \mathrm{SO}_{2}(\mathrm{OR}=1.068,95 \% \mathrm{Cl}$ : 1.014 - 1.126), nitrogen dioxide $\left(\mathrm{NO}_{2}: \mathrm{OR}=1.043,95 \% \mathrm{Cl}: 1.021-1.065\right)$, and $\mathrm{CO}(\mathrm{OR}=1.128,95 \% \mathrm{Cl}: 1.074-1.184)$, especially among females (according to an increase of $10 \mu \mathrm{g} / \mathrm{m}^{3}$ in $\mathrm{PM}_{10}, \mathrm{NO}_{2}, \mathrm{SO}_{2}$, and $1 \mathrm{mg} / \mathrm{m}^{3}$ in $\mathrm{CO}$ exposure). A positive association was observed either in warm or in cold season only for $\mathrm{PM}_{10}$.

Conclusions: Our findings suggest that, in our setting, exposure to ambient levels of air pollution is an important determinant of emergency room (ER) visits for acute respiratory symptoms, particularly during the warm season. ER admittance may be considered a good proxy to evaluate the adverse effects of air pollution on respiratory health.

\section{Background}

The prevalence of respiratory diseases has dramatically increased during the last decades in industrialized countries $[1,2]$ and there is some evidence to correlate both high levels of motor-vehicle emissions and urban lifestyles with the rising trend in respiratory diseases $[3,4]$. Several studies, in Europe [5-7] and elsewhere [8-10], have reported the adverse effects of traffic-related airpollution on human health focusing on particulate

\footnotetext{
* Correspondence: fabio.tramuto@unipa.it

"Department for Health Promotion Sciences "G. D'Alessandro" - Hygiene section, University of Palermo, Via del Vespro 133, 90127 Palermo, Italy Full list of author information is available at the end of the article
}

matter as the most common investigated traffic-related air pollutant [11].

The burden of air pollution on health system is generally underestimated for the difficulties to clearly evaluate the possible linkage between air pollution level and adverse health outcomes partially due to the variability of personal exposure, to the influence of individual effect modifiers [12] but also because respiratory symptoms are often neither consulted nor registered in medical records as related to air pollution [13].

Several epidemiological studies were reported on emergency room (ER) visits and urban air pollution worldwide, but mainly focused on asthma in young age [14-18]. In Italy, the relationship between air pollution

\section{Biomed Central}


and health effects has been previously investigated both in terms of mortality and hospital admission [19-22]. However, fewer studies have analysed more generic endpoints, such as respiratory symptoms in general population, in association with ER admissions [23,24]. The latter ones, that are certainly more frequent events than hospitalisation, could be considered an indicator of urban air pollution associated with a significant worsening in the quality of life, especially in large metropolitan areas $[25,26]$.

In Sicily, the main island of the Mediterranean Sea, Palermo represents the largest metropolitan area. It is characterized by a temperate climate and a very active commercial and touristic port. Due to limited use of domestic heating plants and to the lack of industrial settlements in residential areas, motor vehicles, including boats, contribute to the most part of urban air pollutant emissions, conferring to this geographical setting distinctive key features suitable for modelling studies on traffic-related pollution on health effects.

In the current study, a case-crossover approach was carried out on a three years routinely collected data in order to analyse the association between hospital ER attendance for respiratory causes and traffic-related air pollutants among adult individuals residents of Palermo, the largest city in Sicily (Italy).

\section{Methods}

\section{Geographic setting}

In this study, we considered the municipality of Palermo, a seaside town capital of Sicily, with a resident population of about 700,000 inhabitants $(82.5 \%>14$ years of age, $47.8 \%$ males) [27], and a mediterranean climate with hot summers and temperate winters. Palermo has a very active commercial and tourist port, regular stop of many Mediterranean cruises, and a historic centre characterized by narrow streets and heavy traffic congestion, particularly in rush hours. Due to limited use of domestic heating plants and to the lack of industrial plants in residential areas, motor vehicles, including boats, contributes to at least $70-75 \%$ of total air pollutant emissions [28].

\section{Air pollution and climatic data}

Ten automated fixed-site monitoring stations (seven "urban traffic", two "background", and one meteo-climatic monitoring stations, respectively), located either in densely populated or peripheral urban areas, collected the daily air pollution levels geographically dispersed on a metropolitan area of about $56 \mathrm{~km}^{2}$ (Figure 1) [29].

Data were obtained for particulate matter $(\varnothing \leq 10$ microns - $\mathrm{PM}_{10}$; in $\left.\mu \mathrm{g} / \mathrm{m}^{3}\right)$, nitrogen dioxide $\left(\mathrm{NO}_{2}\right.$; in $\left.\mu \mathrm{g} / \mathrm{m}^{3}\right)$, sulfur dioxide $\left(\mathrm{SO}_{2}\right.$; in $\left.\mu \mathrm{g} / \mathrm{m}^{3}\right)$, and carbon monoxide $\left(\mathrm{CO}\right.$; in $\left.\mathrm{mg} / \mathrm{m}^{3}\right)$. Pollutants were hourly

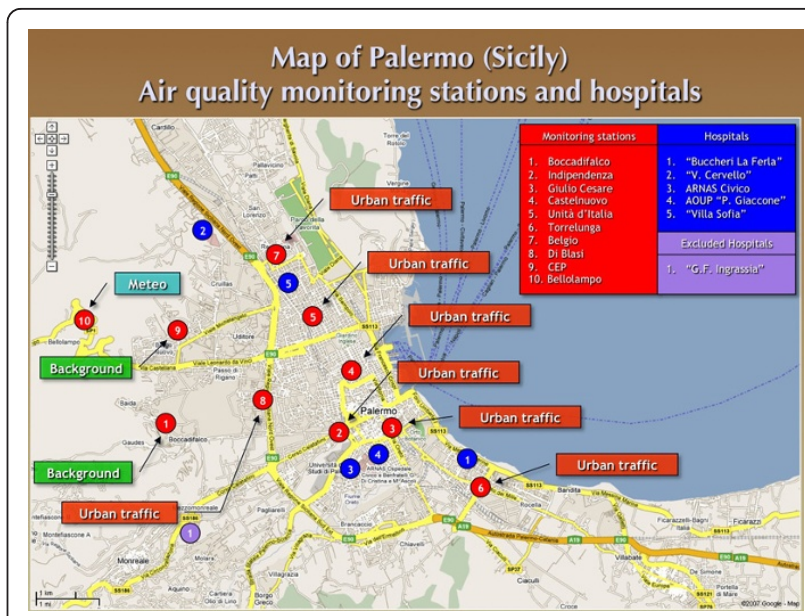

Figure 1 Map of Palermo (Sicily). Air quality monitoring stations and hospitals.

collected by direct gravimetric determination method for $\mathrm{PM}_{10}$, by chemiluminescence for $\mathrm{NO}_{2}$, by ultraviolet fluorescence spectroscopy for $\mathrm{SO}_{2}$, and by infrared-ray absorption for $\mathrm{CO}$.

$\mathrm{PM}_{10}, \mathrm{SO}_{2}, \mathrm{NO}_{2}$ daily mean exposure estimates were used. Exposures to $\mathrm{CO}$ were based on the 8-hours moving average maximum value.

The meteo-climatic monitoring station specifically collected air temperature, relative humidity percent, wind speed, atmospheric pressure, and precipitation.

The completeness criteria for the data recorded at the nine stations were based on estimating the missing value using the available measurements in the other monitoring stations on the same day, weighted by a factor equal to the ratio of the annual mean for the missing station over the corresponding mean from all the other stations available on that particular day [30].

Daily pollution levels were considered missing if any of the other measurements were not available.

Overall, there were less than $10 \%$ of missing values in the air pollutant and meteo-climatic hourly measurements.

\section{Health data}

The inclusion criteria for the selection of partecipating hospitals were: a) location within the city limits of Palermo, b) 24-hour service ER department and emergency physicians, and c) electronic registration of patient admissions.

Overall, six public general hospitals are present in the urban area of Palermo. Of them, five were included in the study, while only one hospital (about 37,000 ER visits/per year) did not meet the third criterion (Figure 1). On the whole, study population accounted for $89.1 \%$ of the ER visits totally collected in Palermo during the period 2005-2007. 
Each participating emergency department provided all their patient data collected between January 2005 and December 2007. Basic data for each patient, only resident of Palermo, included sex, age, and a unique identification (ID) number.

Each ER admission record collected during hospital triage evaluation, which included terms as respiratory deficiency, emphysema, dyspnea/shortness of breath, cough, asthma, pneumonia, bronchopathy, or other obstructive pulmonary diseases, was defined as "event of interest" only if followed by a medical diagnosis of respiratory distress.

Moreover, the number of ER visits by the same person in a day was preliminary checked, and evidence of repeated access was found. Therefore, in order to prevent any possible overestimation of independent visits, although small, only one ER visit per person/day (within each month) was included in the analyses.

\section{Statistical analysis}

Descriptive statistics were calculated for the demographics of patients with ER hospital admission for respiratory disorders and for meteorological factors and air pollutant levels, and a matrix of Pearson's correlation coefficients ( $r$ ) was generated to better define the associations between air pollutants and meteorological parameters.

A case-crossover design [31] was adopted following a time-stratified approach, where for an "event of interest" occurring on a given day of the week, "control days" were considered all the same days of the other weeks throughout the rest of the month. For example, if the subject went to hospital ER on Saturday, all other Saturdays of the same month would be used as controls (thus, three or four days) [32,33].

Stratified analyses were similarly conducted by sex, age-groups (16-44, 45-54, 55-64, 65-74, 75-84, $\geq 85)$, and seasons (winter: October - March, summer: April September).

Moreover, to highlight sufficient variation around a non-zero mean value as suggested in case-crossover studies [34], we calculated the "relevant exposure term" which is the absolute difference between each pollutant's levels corresponding to the "event of interest" ("event days") and its average concentrations over the "control days".

To control for potential impact of meteo-climatic parameters, a same-day mean temperature was used to control for immediate effects and the average of the lags 1-3 of mean temperature to represent the delayed effects.

In the warm season, temperature was considered as daily mean "apparent temperature" (AT), following the methodology described by other authors [35,36].
Because risk may vary non-linearly with temperature, a natural cubic spline (with three degrees of freedom) was used for both the same day and the moving average of the previous three days; both terms were included simultaneously in the models.

The relevant daily data of other meteorogical parameters (relative humidity percent, wind speed, atmospheric pressure, and precipitation) as well as the influenza epidemic peaks, defined between the $3^{\text {rd }}$ and the $7^{\text {th }}$ week of each year (National Surveillance System by the Italian National Institute of Health), were considered as confounding factors.

Pollutant measurements were entered into the analyses as linear variables.

The association between daily levels of traffic-related air pollutants and ER attendance for respiratory causes was analysed by a conditional logistic regression model, and odds ratios (OR) of exposures were calculated to quantify the increase in risk according to an increase of $10 \mu \mathrm{g} / \mathrm{m}^{3}$ in $\mathrm{PM}_{10}, \mathrm{NO}_{2}, \mathrm{SO}_{2}$, and $1 \mathrm{mg} / \mathrm{m}^{3}$ in $\mathrm{CO}$ exposure; $95 \%$ confidence intervals (CI) were calculated.

To examine the hazard period of air pollution for respiratory symptoms, a distributed lag model was also used to evaluate the effect of air pollutants; the hazard period was defined as the same day (lag 0), or the previous day up to the $5^{\text {th }}$ day prior to the hospital visit.

Finally, risk estimates were calculated by using a single pollutant model, given the general collinearity between the pollutants.

All statistical analyses were conducted using STATA v10.1 MP for Macintosh (Apple) by using the CLOGIT command [37].

\section{Results}

"Events of interest" were recorded in 48,519 out of $1,014,272$ (5\%) ER visits accounting for a mean number of daily admissions of 44.9 (range: 17-96), with a higher proportion of visits during the winter (53.1\%). Moreover, about $53 \%$ of visits occurred in individuals $\leq 64$ years of age, with a fairly predominance of males (55.5\%). 608 (1.2\%) ER visits were excluded as duplicates within the same day by individual patients (Table 1 ).

Table 2 summarize the descriptive statistics of the urban air pollutant levels and meteo-climatic variables. Daily average concentrations of $\mathrm{SO}_{2}, \mathrm{NO}_{2}$, and $\mathrm{CO}$ were costantly lower than the law's threshold in Italy [38]; the daily mean level of $\mathrm{PM}_{10}$ was $36.0 \mu \mathrm{g} / \mathrm{m}^{3}$ (annual law limit $=40 \mu \mathrm{g} / \mathrm{m}^{3}$ ) although, on a cumulative basis, about $45 \%$ of the daily observations exceeded threshold.

Moreover, a consistent difference was observed between the mean daily levels of each pollutant registered in the "event days" and "control days", respectively. 
Table 1 Descriptive statistics of ER hospital admissions for respiratory symptoms in total and by year, age-group, sex, and season

\begin{tabular}{|c|c|c|}
\hline Characteristic & Number of visits & (\%) \\
\hline ER admissions for all causes & $1,014,272$ & \\
\hline ER admissions for respiratory symptoms & 49,127 & \\
\hline 2005 & 16,960 & $(34.5)$ \\
\hline 2006 & 15,932 & $(32.4)$ \\
\hline 2007 & 16,235 & $(33,1)$ \\
\hline Daily ER admissions [mean (range)] & $44.9(17-96)$ & \\
\hline Duplicates within the same day for each study subject & 608 & $(1.2)$ \\
\hline Total ER visits w/o same day duplicates & 48,519 & \\
\hline \multicolumn{3}{|l|}{ Season } \\
\hline Warm (April to September) & 22,759 & $(46.9)$ \\
\hline Cold (October to March) & 25,760 & $(53.1)$ \\
\hline \multicolumn{3}{|l|}{ Age group (years) } \\
\hline $16-44$ & 14,988 & $(30,9)$ \\
\hline $45-54$ & 4,698 & $(9.7)$ \\
\hline $55-64$ & 5,936 & $(12.2)$ \\
\hline $65-74$ & 9,236 & $(19.0)$ \\
\hline $75-84$ & 10,139 & $(20.9)$ \\
\hline$\geq 85$ & 3,522 & $(7.3)$ \\
\hline Age subjects [years, mean (SD)] & $56.4(37)$ & \\
\hline \multicolumn{3}{|l|}{ Sex } \\
\hline Female & 21,516 & $(44.4)$ \\
\hline Male & 26,934 & $(55.5)$ \\
\hline (missing) & 69 & $(0.1)$ \\
\hline
\end{tabular}

Table 2 Statistics for urban air pollutant, weather variables, and distribution of the absolute differences between the daily levels of each pollutant ("event days") and the average concentrations over the "control days".

\begin{tabular}{|c|c|c|c|c|c|c|c|}
\hline \multirow[t]{2}{*}{ Parameter } & \multirow[t]{2}{*}{ Unit } & \multirow[t]{2}{*}{ Mean } & \multicolumn{5}{|c|}{ Percentiles } \\
\hline & & & 10 & 25 & 50 & 75 & 90 \\
\hline \multicolumn{8}{|l|}{ Pollutants } \\
\hline $\mathrm{PM}_{10}$ & $\mu \mathrm{g} / \mathrm{m}^{3}$ & $36.0^{*}$ & 21.6 & 26.3 & 33.2 & 41.5 & 52.6 \\
\hline $\mathrm{NO}_{2}$ & $\mu \mathrm{g} / \mathrm{m}^{3}$ & 41.5 & 24.8 & 32.7 & 40.8 & 49.7 & 58.6 \\
\hline $\mathrm{SO}_{2}$ & $\mu \mathrm{g} / \mathrm{m}^{3}$ & 3.4 & 0.6 & 1.2 & 2.6 & 4.5 & 6.9 \\
\hline $\mathrm{CO}$ & $\mathrm{mg} / \mathrm{m}^{3}$ & 1.1 & 0.4 & 0.6 & 0.9 & 1.5 & 2.1 \\
\hline \multicolumn{8}{|c|}{ Differences "event-control" days } \\
\hline $\mathrm{PM}_{10}$ & $\mu \mathrm{g} / \mathrm{m}^{3}$ & 11.8 & 1.4 & 4.2 & 8.9 & 15.6 & 24.1 \\
\hline $\mathrm{NO}_{2}$ & $\mu \mathrm{g} / \mathrm{m}^{3}$ & 10.8 & 1.7 & 4.1 & 9.0 & 15.2 & 22.1 \\
\hline $\mathrm{SO}_{2}$ & $\mu \mathrm{g} / \mathrm{m}^{3}$ & 2.2 & 0.3 & 0.6 & 1.4 & 2.8 & 5.0 \\
\hline $\mathrm{CO}$ & $\mathrm{mg} / \mathrm{m}^{3}$ & 0.4 & 0.0 & 0.1 & 0.3 & 0.6 & 0.9 \\
\hline \multicolumn{8}{|l|}{ Weather variables } \\
\hline Air temperature & ${ }^{\circ} \mathrm{C}$ & 18.6 & 10.7 & 13.3 & 18.7 & 23.8 & 26.7 \\
\hline Relative humidity $\%$ & $\%$ & 58.8 & 44.2 & 51.3 & 59.8 & 66.9 & 72.1 \\
\hline Atmospheric pressure & mbars & 994.2 & 987.6 & 990.7 & 993.9 & 997.8 & 1001.3 \\
\hline Precipitation & $\mathrm{mm}$ & 0.1 & 0.0 & 0.0 & 0.0 & 0.0 & 0.3 \\
\hline Wind speed & $\mathrm{m} / \mathrm{s}$ & 3.2 & 1.6 & 2.0 & 2.6 & 4.1 & 6.1 \\
\hline
\end{tabular}

January 2005 - December 2007.

*on a cumulative basis, about $45 \%$ of the daily observations exceeded threshold. 
During the study period the climate was temperate, with a mean air temperature of $18.6^{\circ} \mathrm{C}$ and a relative humidity of $58.8 \%$, with little rain or wind.

There was moderately high collinearity among pollutants, including $\mathrm{SO}_{2}$ and $\mathrm{NO}_{2}(\mathrm{r}=0.571), \mathrm{PM}_{10}$ and $\mathrm{NO}_{2}(\mathrm{r}=0.451)$, and especially $\mathrm{CO}$ and $\mathrm{NO}_{2}(\mathrm{r}=0.592)$.

Rain correlated negatively with all pollutants, whereas relative humidity percent did not. $\mathrm{PM}_{10}, \mathrm{SO}_{2}$, and $\mathrm{NO}_{2}$ did not follow a seasonal pattern and were not correlated with temperature (see Additional file 1: Matrix of linear correlation coefficients, Table S1 for an overview of all variables). Moreover, the monthly levels of the pollutants measured during the study period are reported in Additional file 2: Monthly distribution of the pollutants, Figure S1.

Table 3 reports the associations between air pollution exposure and respiratory effects calculated for the single pollutant model, by controlling the influence of different climatic parameters and influenza epidemic peaks.

In the full year analysis, positive effect estimates were found with all the pollutants, showing an increased risk of $2.2 \%$ (95\% CI: $1.3-3.1$ ), $4.4 \%$ (95\% CI: $0.3-8.6$ ), $2.3 \%$ (95\% CI: 0.1-4.7) and 1.5\% (95\% CI: 0.4-2.6) for $\mathrm{PM}_{10}$, $\mathrm{SO}_{2}, \mathrm{CO}$ and $\mathrm{NO}_{2}$, respectively. Stronger associations were observed during the summer with increments ranging from $3.9 \%$ to $12.8 \%$; only $\mathrm{PM}_{10}$ demonstrated a clear association in the cold season too.

Moreover, risk estimates decreased over time for each pollutant at different lags (0-5 days prior to ER visit), and mostly the same day exposure was significant; therefore, lag 0 exposure will be considered as the hazard time (Figure 2).

For each pollutant, analyses were replicated for different age groups and sex (Figure 3 and 4). Overall, the most marked associations between ER visits and $\mathrm{PM}_{10}$ air pollution levels occurred among the age groups 16-44 years and $\geq 85$ years during the summer $(\mathrm{OR}=1.059,95 \% \mathrm{CI}$ : 1.023-1.096 and OR $=1.087,95 \%$ CI: $1.015-1.165$, respectively), preferentially among women $(\mathrm{OR}=1.064,95 \% \mathrm{CI}$ : $1.012-1.119$ and $\mathrm{OR}=1.121$, 95\% CI: 1.023-1.229).
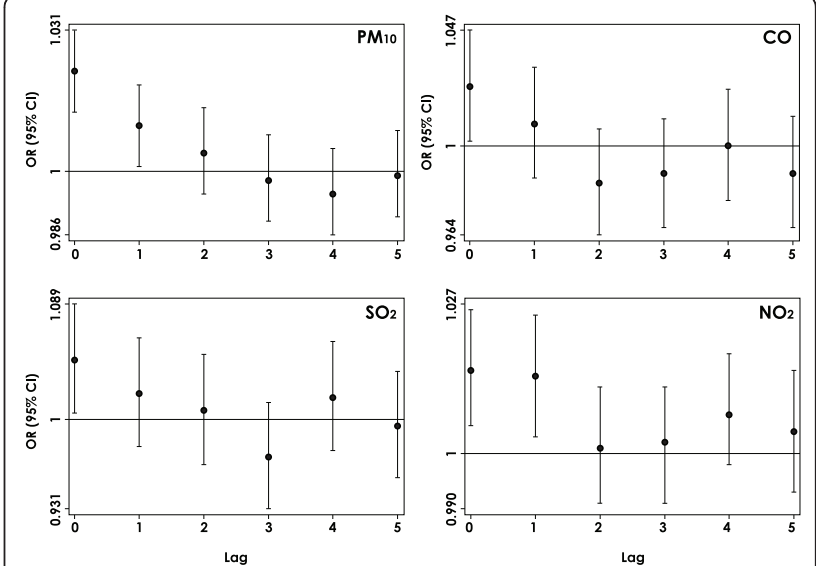

Figure 2 Odds ratio (OR) for emergency respiratory symptoms calls according to various lag times, Palermo, Sicily, 2005-2007. Lag 0 is for pollutant concentrations averaged on the day of the call, lag 1 is for pollutant concentrations averaged for the previous day of the call, and so on. Associations are expressed as adjusted OR [95\% confidence interval $(\mathrm{Cl})]$ in relation to an increase of 10 $\mathrm{\mu g} / \mathrm{m}^{3}$ of selected air pollutants (CO: an increase of $1 \mathrm{mg} / \mathrm{m}^{3}$ ). ORs adjusted for meteo-climatic parameters, and influenza epidemic peaks (see Methods - Statistical analysis).

A similar result was also observed in females 75-84 years old for the $\mathrm{SO}_{2}(\mathrm{OR}=1.222$, 95\% CI: 1.026-1.457), while the highest OR values were observed with $\mathrm{CO}$ exposure $(\mathrm{OR}=1.292 ; 95 \% \mathrm{CI}: 1.127-1.481)$ among females and during the warm season.

\section{Discussion}

In this study, a positive association between ER attendance for respiratory symptoms and ambient exposure to motor-vehicle pollutants such as $\mathrm{PM}_{10}$, nitrogen dioxide, sulfure oxide, and carbon monoxide was found, and a clear difference by season was observed. $\mathrm{PM}_{10}$ was the sole pollutant that showed positive OR values in both the warm and cold seasons.

Villeneuve et al. [14] described a positive association for asthma visits with outdoor air pollution levels but

Table 3 Adjusted odds ratio (OR) ${ }^{\mathrm{a}}$ for emergency department visits for respiratory causes among all patients, by season

\begin{tabular}{|c|c|c|c|c|c|c|}
\hline \multirow[b]{3}{*}{ Pollutants } & \multicolumn{2}{|c|}{ All seasons } & \multicolumn{4}{|c|}{ Season } \\
\hline & \multirow[b]{2}{*}{ OR } & \multirow[b]{2}{*}{$95 \% \mathrm{Cl}$} & \multicolumn{2}{|c|}{ Cold (October to March) } & \multicolumn{2}{|c|}{ Warm (April to September) } \\
\hline & & & OR & $95 \% \mathrm{Cl}$ & OR & $95 \% \mathrm{Cl}$ \\
\hline $\mathrm{PM}_{10}$ & 1.022 & $1.013-1.031$ & 1.018 & $1.008-1.029$ & 1.039 & $1.020-1.058$ \\
\hline $\mathrm{SO}_{2}$ & 1.044 & $1.003-1.086$ & 0.983 & $0.908-1.064$ & 1.068 & $1.014-1.126$ \\
\hline $\mathrm{CO}^{\mathrm{b}}$ & 1.023 & $1.001-1.047$ & 0.991 & $0.965-1.017$ & 1.128 & $1.074-1.184$ \\
\hline $\mathrm{NO}_{2}$ & 1.015 & $1.004-1.026$ & 1.000 & $0.984-1.015$ & 1.043 & $1.021-1.065$ \\
\hline
\end{tabular}

${ }^{a}$ Odds ratios were calculated in relation to an increase of $10 \mu \mathrm{g} / \mathrm{m}^{3}$ of selected air pollutants and were adjusted for meteo-climatic parameters, and influenza epidemic peaks (see Methods - Statistical analysis).

${ }^{b}$ For an increase of $1 \mathrm{mg} / \mathrm{m}^{3}$. 


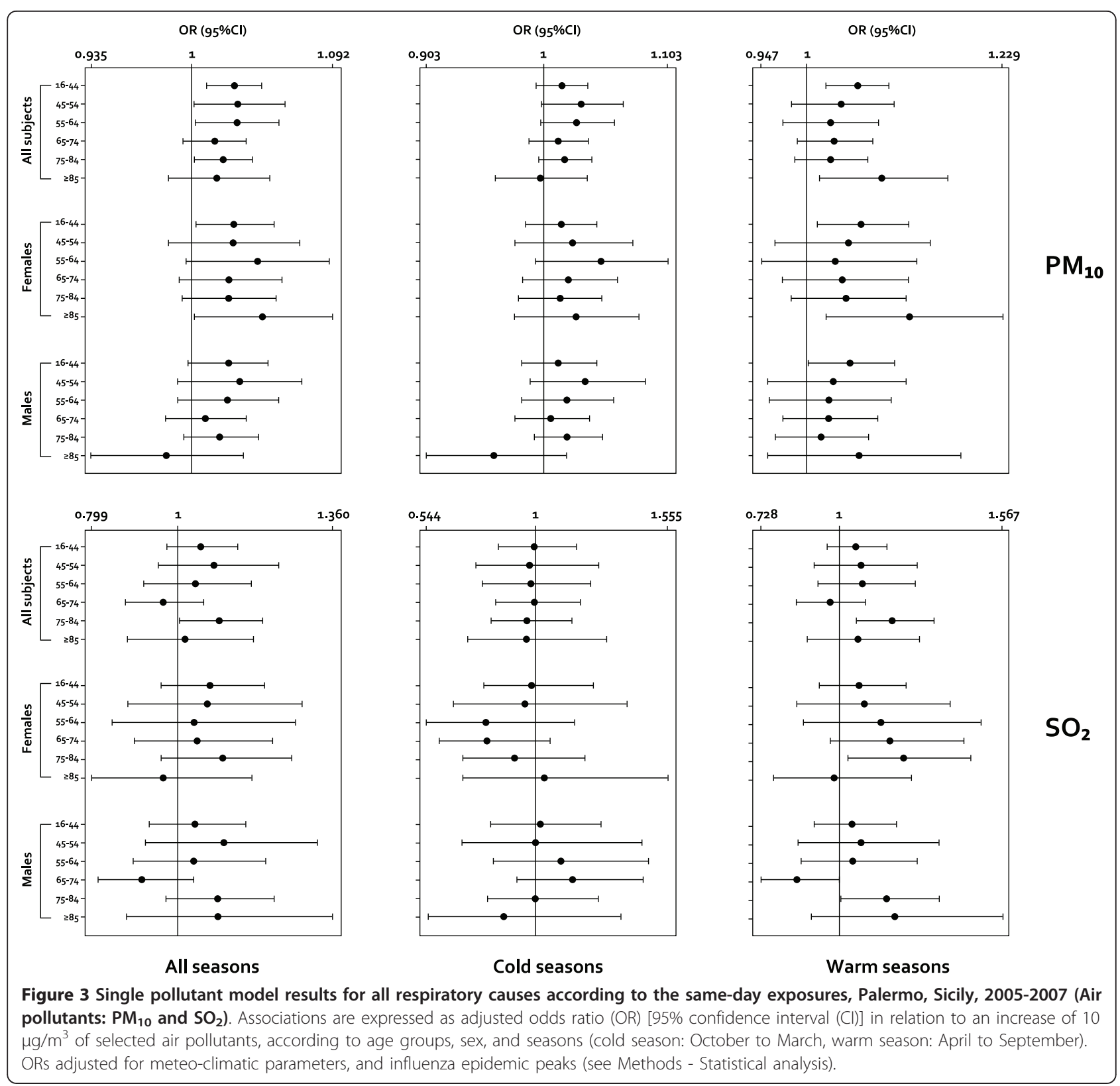

only during the warm season, documenting similar results with higher OR values among elderly individuals (OR $=1.09$ vs 1.10 , respectively). In contrast, Fusco et al. [39] did not report any overall effect with same-day levels of suspended particles for total respiratory admissions.

Zanobetti et al. [35], using a case-crossover approach, found a significant association between black carbon and pneumonia hospitalization (11.7\% increase of risk). However, they found no associations with pneumonia ER admissions in the warm season.

In Italy, Bedeschi et al. [23] reported a 2.7\% increase of risk between $\mathrm{PM}_{10}$ exposure and ER visits for all respiratory disorders, even if among children and at lag 3 ; however, the delayed time observed might raise specific considerations in a such particular setting of individuals.

Different considerations have to point out on sulfur dioxide. Air concentration of this gaseous pollutant has been drastically decreased worldwide $[40,41]$ due to the adoption of low-sulphur fuels for urban vehicle engines. Consequently, it could be considered of minor importance in the evaluation of the possible linkage between traffic related air pollution and health effects. However, since new regulations in maritime transportation haven't been fully implemented yet, sea 


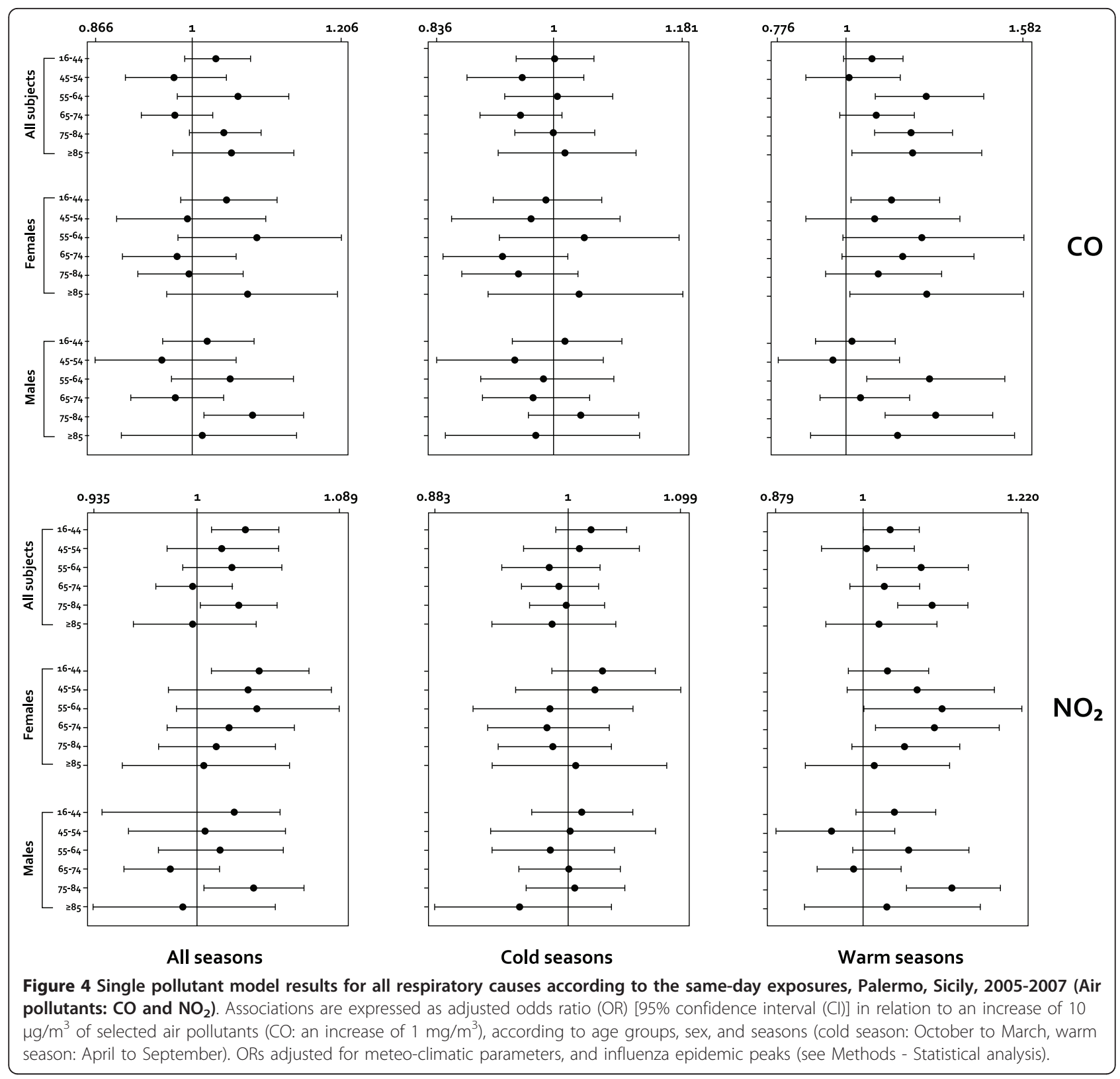

transports may be actually considered the most important source of $\mathrm{SO}_{2}$ pollution in deep-rooted maritime vocation cities $[42,43]$. In our context, where the port is located not far from the city centre and a heavy maritime traffic is present from spring through early autumn, the potential effects of ambient $\mathrm{SO}_{2}$ levels on respiratory health cannot be excluded. Therefore, $\mathrm{SO}_{2}$ was considered in the analyses reported in the present study.

The effects of $\mathrm{SO}_{2}$ on respiratory hospitalization varies considerably, especially at low levels of exposure, and conflicting results were documented by several authors $[14,44,45]$.
Wong et al. [46] observed significant short-term effects between $\mathrm{SO}_{2}$ and admissions for respiratory causes in elderly subjects but not among younger age groups. Consistent with these findings, our study showed a positive association between $\mathrm{SO}_{2}$ and respiratory events among elderly individuals, especially in warm season, confirming the possible role of maritime traffic pollution in coastal cities as also observed in North Europe [42].

Overall, a significant association was observed between $\mathrm{CO}$ exposure and respiratory disorders especially in the warm season $(\mathrm{OR}=1.128,95 \% \mathrm{CI}: 1.074-1.184)$, as similarly reported in large metropolitan centres either in 
Italy or elsewhere [14,39,46], while Bedeschi et al. [23] found no association between $\mathrm{CO}$ and respiratory ER visits among children.

$\mathrm{NO}_{2}$ has been known to increase susceptibility to respiratory infections [47].

Positive associations were observed both in France [48] and in Rome [39] particularly during the summer, as well as in England although at lag2 and in infants [49]. On the contrary, no significant associations were reported, also in different groups of age, either in London [50] or in northern Alberta (Canada) [14].

In our setting, $\mathrm{NO}_{2}$ correlated with increasing respiratory symptoms mostly in summer but without a clear age dependence.

Environmental exposures are complex. Traffic-related air pollution includes gaseous species and PM from combustion, tire and brake wear, and resuspended roadway dusts. Moreover, because there is a strong correlation between different pollutants regularly investigated in environmental studies [44], it is usually difficult to glean the contribution of each pollutant on health effects.

Furthermore, quality and distribution of air pollutants could be probably affected by the geo-orographical characteristics, human activities, and climatic conditions that may vary between cities. Thus, concomitant causes could explain the partial inconsistency in the results of the various investigations.

Although studies on air pollution and health were historically carried out by using a time series design, the case-crossover approach has been increasingly applied more recently [51]. In our study, values relative to the "relevant exposure term" were also calculated for each pollutant to evaluate the presence of sufficient variation around a non-zero mean value between ambient concentrations of event and control days, since a scarse variability between event and control days could lead to a wrong interpretation of the results, limiting the power to detect health effects [34].

Moreover, because some controversies regarding the use of multipollutant modelling in air pollutant research were raised [39], in this study we applied a monopollutant regression model controlling for different meteo-climatic variables and flu epidemic peaks as possible confounders. Furthermore, we have preliminarly checked the effect of air pollutants without meteo-climatic factors in the logistic regression model. Not surprisingly, we found stronger effects with temperature, considering the climate of our geographic area characterized by hot and humid summers.

Overall, the present study documented a strong seasonality of air pollution effects on human respiratory health. According to other authors [52,53], this could be partially explained as the warm season represents the period when individuals spend a greater portion of their time outdoor dedicated to physical activity practice, resulting in higher respiratory volumes and exposure to ambient pollution.

More elevated risk estimates were observed among females, although the reasons for these differences are yet unclear and the literature is far from consistent. However, there is growing epidemiologic evidence of differing associations between air pollution and respiratory health for females and males and suggestive interpretations have been proposed for existing differences in relation to sex [54].

It is unclear whether observed modification is attributable primarily to sex-linked biological distinctions, to work-related exposure differences between men and women (e.g. cooking exhaust and cleaning products), to socially derived activities and roles, or to some interplay thereof.

Hormonal status or differences in the rates of lung growth and decline may influence vascular functions [55] or inflammation of the respiratory tract $[56,57]$. Moreover, the deposition of air pollution particles in the lung has been shown to be greater in females compared with males, leading to a more female susceptibility to respiratory diseases $[58,59]$. Furthermore, in Sicily, because some domestic jobs continue to be usually performed by women such as cooking, dusting, cleaning, and child care, these and other reasons might lead women to show greater health effects to air-related risk factors.

Finally, at least three limitations of this study could be considered. Firstly, we were not able to separately investigate the effects of individual behaviours, as possible confounders, such as tobacco use, because informations usually were not available in ER admission archives.

Secondly, the lack of ICD codes in admission records might have affected the ability to critically choose the "events of interest".

Thirdly, for each air pollutant, a single value was averaged by a fixed number of monitoring stations instead of individual passive samplers for personal exposure measurements, leading to a spatial misalignment between pollutants levels and health data.

However, the distribution of pollutants throughout the study area was preliminarly checked by calculating a set of both correlation and concordance coefficients between pair of monitoring stations, showing a strong homogeneity in the pollutant distribution (mean $\mathrm{r}=$ 0.801 ; range: $0.687-0.900$ ).

Nevertheless, this study implicates motor-vehicle emissions as a relevant indicator of urban air pollution and as a determinant of deterioration of respiratory health status with evidence of exacerbation in the warm season. These findings persisted after adjustment for meteo-climatic variables and seasonal flu epidemics. 
Our results specifically incremented the evidence of association between air pollution exposure and shortterm respiratory health effects in a residential area characterized by the lack of industrial settlements and by a limited use of domestic heating plants.

Although these results must be interpreted with caution, they can provide helpful information to the field of public health and may have implications for local environmental and social policies.

\section{Conclusions}

This study suggests that, in our setting, urban air pollution exposure is an important determinant of ER visits for acute respiratory symptoms. Air pollution effects are not homogenous and differences in the magnitude might be associated with different seasons and agegroups. Moreover, the study shows that warm season increases the risk of respiratory health effects due to motor vehicle-related air pollution, especially in females.

ER admittance may be considered a good proxy to evaluate the adverse effects of air pollution on respiratory health and the identification of sex-related susceptible groups reinforces the need for public policy measures to better control air pollution.

\section{Additional material}

Additional file 1: Table S1 Matrix of linear correlation coefficients.

Text document that provides a matrix of linear correlation coefficients between urban air pollutants and weather variables. January 2005 December 2007.

Additional file 2: Figure S1 Monthly distribution of the pollutants EPS File that shows the monthly distribution of the pollutants over the three-year period.

\section{List of abbreviations}

AT: apparent temperature; $\mathrm{Cl}$ : confidence interval; CO: carbon monoxide; ER: emergency room; ID: identification number; OR: odds ratio; PM: particulate matter; Press: Atmospheric pressure; $\mathrm{NO}_{2}$ : nitrogen dioxide; Prec: Precipitation; r: Pearson's correlation coefficient; $\mathrm{RH} \%$ : relative humidity \%; $\mathrm{SO}_{2}$ : sulfur dioxide; Temp: Air temperature; Wind: wind speed;

\section{Acknowledgements}

Fabio Tramuto was partially supported by the Master in Epidemiology, University of Turin and San Paolo Foundation.

The authors thank Prof. Rossella Miglio and Prof. Franco Merletti for their scientific and technical support.

The authors like to thank all members of the APRES (Air Pollution and Respiratory Syndromes) Study Group:

Luigi Aprea, Salvatore Paterna, Vittorio Giuliano (A.O.U.P. "P. Giaccone" Palermo); Giovanna Volo, Michelangelo Pecorella (A.R.N.A.S. Civico - Palermo); Gabriella Filippazzo, Manlio De Simone (Az. Osp. "V. Cervello" - Palermo); Salvatore Requirez, Baldassare Seidita (Az. Osp. "Villa Sofia"); Giampiero Seroni, Michele Zagra (Az. Osp. "Buccheri La Ferla).

\section{Author details}

'Department for Health Promotion Sciences "G. D'Alessandro" - Hygiene section, University of Palermo, Via del Vespro 133, 90127 Palermo, Italy.

${ }^{2}$ Department of Public Health, Epidemiology and Preventive Medicine - ASP6
Palermo, Via Siracusa 45, 90141 Palermo, Italy. ${ }^{3}$ Palermo Province Cancer Registry, Department for Health Promotion Sciences "G. D'Alessandro" Hygiene section, University of Palermo, Via del Vespro 133, 90127 Palermo, Italy. ${ }^{4}$ AMIA SpA, Via Pietro Nenni 28, 90146 Palermo, Italy.

\section{Authors' contributions}

FT participated in the design of the study, contributed in the acquisition of air pollution/health data, performed the statistical analysis, and helped to draft the manuscript. RC participated in the design of the study and helped to draft the manuscript. GCE participated in the design of the study and in the acquisition of air pollution/health data. MV carried out the modeling of traffic, congestion, and emissions. GCA contributed in the acquisition of air pollution/health data. CMM helped to draft the manuscript. FV conceived of the study, participated in its design and coordination, and helped to draft the manuscript. All authors read and approved the final manuscript.

\section{Competing interests}

The authors declare that they have no competing interests.

Received: 16 November 2010 Accepted: 13 April 2011

Published: 13 April 2011

\section{References}

1. Sunyer J: Urban air pollution and chronic obstructive pulmonary disease: a review. Eur Respir J 2001, 17:1024-1033.

2. Sicard $P$, Mangin $A$, Hebel $P$, Malléa $P$ : Detection and estimation trends linked to air quality and mortality on French Riviera over the 1990-2005 period. Sci Total Environ 2010, 408:1943-1950.

3. Samet J, Krewski D: Health effects associated with exposure to ambient air pollution. J Toxicol Environ Health A 2007, 70:227-242, Review.

4. D'Amato G, Cecchi L, D'Amato M, Liccardi G: Urban air pollution and climate change as environmental risk factors of respiratory allergy: an update. J Investig Allergol Clin Immunol 2010, 20:95-102, Review.

5. Zmirou D, Gauvin S, Pin I, Momas I, Sahraoui F, Just J, Le Moullec Y, Brémont $F$, Cassadou S, Reungoat $P$, Albertini M, Lauvergne N, Chiron M, Labbé A, Vesta Investigators: Traffic related air pollution and incidence of childhood asthma: results of the Vesta case-control study. J Epidemiol Community Health 2004, 58:18-23.

6. Künzli N, Bridevaux PO, Liu LJ, Garcia-Esteban R, Schindler C, Gerbase MW, Sunyer J, Keidel D, Rochat T, Swiss Cohort Study on Air Pollution and Lung Diseases in Adults: Traffic-related air pollution correlates with adult-onset asthma among never-smokers. Thorax 2009, 64:664-670.

7. Linares B, Guizar JM, Amador N, Garcia A, Miranda V, Perez JR, Chapela R: Impact of air pollution on pulmonary function and respiratory symptoms in children. Longitudinal repeated-measures study. BMC Pulm Med 2010, 10:62

8. Mann JK, Balmes JR, Bruckner TA, Mortimer KM, Margolis HG, Pratt B, Hammond SK, Lurmann FW, Tager IB: Short-term effects of air pollution on wheeze in asthmatic children in Fresno, California. Environ Health Perspect 2010, 118:1497-1502

9. Atkinson RW, Fuller GW, Anderson HR, Harrison RM, Armstrong B: Urban ambient particle metrics and health: a time-series analysis. Epidemiology 2010, 21:501-511.

10. Stieb DM, Szyszkowicz M, Rowe BH, Leech JA: Air pollution and emergency department visits for cardiac and respiratory conditions: a multi-city time-series analysis. Environ Health 2009, 8:25.

11. Morgenstern V, Zutavern A, Cyrys J, Brockow I, Gehring U, Koletzko S, Bauer CP, Reinhardt D, Wichmann HE, Heinrich J: Respiratory health and individual estimated exposure to traffic-related air pollutants in a cohort of young children. Occup Environ Med 2007, 64:8-16.

12. Forastiere F, Stafoggia M, Berti G, Bisanti L, Cernigliaro A, Chiusolo M, Mallone S, Miglio R, Pandolfi P, Rognoni M, Serinelli M, Tessari R, Vigotti M, Perucci CA, SISTI Group: Particulate matter and daily mortality: a casecrossover analysis of individual effect modifiers. Epidemiology 2008, 19:571-580.

13. Yunesian M, Asghari F, Vash JH, Forouzanfar MH, Farhud D: Acute symptoms related to air pollution in urban areas: a study protocol. BMC Public Health 2006, 6:218.

14. Villeneuve PJ, Chen L, Rowe BH, Coates F: Outdoor air pollution and emergency department visits for asthma among children and adults: a 
case-crossover study in northern Alberta, Canada. Environ Health 2007 6:40.

15. Moore K, Neugebauer R, Lurmann F, Hall J, Brajer V, Alcorn S, Tager I: Ambient ozone concentrations cause increased hospitalizations for asthma in children: an 18-year study in Southern California. Environ Health Perspect 2008, 116:1063-1070.

16. Pereira G, Cook A, De Vos AJ, Holman CD: A case-crossover analysis of traffic-related air pollution and emergency department presentations for asthma in Perth, Western Australia. Med J Aust 2010, 193:511-514.

17. Carlsten C, Dybuncio A, Becker A, Chan-Yeung M, Brauer M: Traffic-related air pollution and incident asthma in a high-risk birth cohort. Occup Environ Med 2010

18. Strickland MJ, Darrow LA, Klein M, Flanders WD, Sarnat JA, Waller LA, Sarnat SE, Mulholland JA, Tolbert PE: Short-term associations between ambient air pollutants and pediatric asthma emergency department visits. Am J Respir Crit Care Med 2010, 182:307-316.

19. Faustini A, Stafoggia M, Berti G, Bisanti L, Chiusolo M, Cernigliaro A, Mallone S, Primerano R, Scarnato C, Simonato L, Vigotti MA, Forastiere F, EPIAIR collaborative Group: The relationship between ambient particulate matter and respiratory mortality: a multi-city study in Italy. Eur Respir J 2011.

20. Cadum E, Berti G, Biggeri A, Bisanti L, Faustini A, Forastiere F, Gruppo collaborativo EpiAir: [The results of EpiAir and the national and international literature]. In Epidemiol Prev. Volume 33. Italian; 2009:(6 Suppl 1):113-119, 123-143.

21. Colais P, Serinelli M, Faustini A, Stafoggia M, Randi G, Tessari R, Chiusolo M, Pacelli B, Mallone S, Vigotti MA, Cernigliaro A, Galassi C, Berti G, Forastiere F, Gruppo collaborativo EpiAir: [Air pollution and urgent hospital admissions in nine Italian cities. Results of the EpiAir Project]. In Epidemiol Prev. Volume 33. Italian; 2009:(6 Suppl 1):77-94.

22. Biggeri A, Bellini $P$, Terracini B: [Meta-analysis of the Italian studies on short-term effects of air pollution-MISA 1996-2002]. In Epidemiol Prev. Volume 28. Italian; 2004:(4-5 Suppl):4-100

23. Bedeschi E, Campari C, Candela S, Collini G, Caranci N, Frasca G, Galassi C, Francesca G, Vigotti MA: Urban air pollution and respiratory emergency visits at pediatric unit, Reggio Emilia, Italy. J Toxicol Environ Health A 2007, 70:261-265.

24. Vigotti MA, Chiaverini F, Biagiola P, Rossi G: Urban air pollution and emergency visits for respiratory complaints in Pisa, Italy. J Toxicol Environ Health A 2007, 70:266-269.

25. Abe T, Tokuda Y, Ohde S, Ishimatsu S, Nakamura T, Birrer RB: The relationship of short-term air pollution and weather to ED visits for asthma in Japan. Am J Emerg Med 2009, 27:153-159.

26. Orazzo F, Nespoli L, Ito K, Tassinari D, Giardina D, Funis M, Cecchi A, Trapani C, Forgeschi G, Vignini M, Nosetti L, Pigna S, Zanobetti A: Air pollution, aeroallergens, and emergency room visits for acute respiratory diseases and gastroenteric disorders among young children in six Italian cities. Environ Health Perspect 2009, 117:1780-1785.

27. ISTAT: $14^{\circ} \mathrm{Censimento}$ della popolazione e delle abitazioni. 2001

28. Istituto Superiore per la Protezione e la Ricerca Ambientale: Qualità dell'ambiente urbano. VI Rapporto ISPRA. 2009

29. AMIA SpA, Palermo - Italy. [http://www.amianet.it].

30. Katsouyanni K, Schwartz J, Spix C, Touloumi G, Zmirou D, Zanobetti A Wojtyniak B, Vonk JM, Tobias A, Pönkä A, Medina S, Bachárová L, Anderson HR: Short term effects of air pollution on health: a European approach using epidemiologic time series data: the APHEA protocol. $J$ Epidemiol Community Health 1996, 50(Suppl 1):S12-18.

31. Maclure M: The case-crossover design: a method for studying transient effects on the risk of acute events. Am J Epidemiol 1991, 133:144-153.

32. Levy D, Lumley T, Sheppard L, Kaufman J, Checkoway H: Referent selection in case-crossover analyses of acute health effects of air pollution. Epidemiology 2001, 12:186-192.

33. Janes $H$, Sheppard L, Lumley $T$ : Case-crossover analyses of air pollution exposure data: referent selection strategies and their implications for bias. Epidemiology 2005, 16:717-726.

34. Künzli N, Schindler C: A call for reporting the relevant exposure term in air pollution case-crossover studies. J Epidemiol Community Health 2005, 59:527-530, Review.

35. Zanobetti A, Schwartz J: Air pollution and emergency admissions in Boston, MA. J Epidemiol Community Health 2006, 60:890-895.
36. Stafoggia M, Forastiere F, Agostini D, Biggeri A, Bisanti L, Cadum E, Caranci N, de'Donato F, De Lisio S, De Maria M, Michelozzi P, Miglio R, Pandolfi P, Picciotto S, Rognoni M, Russo A, Scarnato C, Perucci CA: Vulnerability to heat-related mortality: a multicity, population-based, case-crossover analysis. Epidemiology 2006, 17:315-323.

37. StataCorp: Stata Statistical Software: Release 10. College Station, TX: StataCorp LP. 2007.

38. GURI (Gazzetta Ufficiale Repubblica Italiana): Recepimento della direttiva 1999/30/CE del Consiglio del 22/4/1999 concernente i valori limite di qualità dell'aria ambiente per il biossido di zolfo, biossido di azoto, ossidi di azoto, le particelle e il piombo e della direttiva 2000/69/CE relativa ai valori limite di qualità dell'aria ambiente per il benzene ed il monossido di carbonio. Decreto Ministero Ambiente e Tutela del Territorio 2/ 4/2002 no 602002

39. Fusco D, Forastiere F, Michelozzi P, Spadea T, Ostro B, Arcà M, Perucci CA: Air pollution and hospital admissions for respiratory conditions in Rome, Italy. Eur Respir J 2001, 17:1143-1150.

40. Vestreng V, Myhre G, Fagerli H, Reis S, Tarraso L: Twenty-five years of continuous sulphur dioxide emission reduction in Europe. Atmos Chem Phys Discuss 2007, 7:5099-5143.

41. Health Effects Institute: Traffic-Related Air Pollution: A Critical Review of the Literature on Emissions, Exposure, and Health Effects. Special Report 17. 2010.

42. Matthias V, Bewersdorff I, Aulinger A, Quante M: The contribution of ship emissions to air pollution in the North Sea regions. Environ Pollut 2010, 158:2241-2250

43. Lonati G, Cernuschi S, Sidi S: Air quality impact assessment of at-berth ship emissions: Case-study for the project of a new freight port. Sci Total Environ 2010, 409:192-200.

44. Luginaah IN, Fung KY, Gorey KM, Webster G, Wills C: Association of ambient air pollution with respiratory hospitalization in a governmentdesignated "area of concern": the case of Windsor, Ontario. Environ Health Perspect 2005, 113:290-296

45. Sunyer J, Atkinson R, Ballester F, Le Tertre A, Ayres JG, Forastiere F, Forsberg B, Vonk JM, Bisanti L, Anderson RH, Schwartz J, Katsouyanni K, APHEA 2 study: Respiratory effects of sulphur dioxide: a hierarchical multicity analysis in the APHEA 2 study. Occup Environ Med 2003, 60:e2.

46. Wong TW, Lau TS, Yu TS, Neller A, Wong SL, Tam W, Pang SW: Air pollution and hospital admissions for respiratory and cardiovascular diseases in Hong Kong. Occup Environ Med 1999, 56:679-683.

47. Speizer FE, Ferris B Jr, Bishop YM, Spengler J: Respiratory disease rates and pulmonary function in children associated with $\mathrm{NO}_{2}$ exposure. Am Rev Respir Dis 1980, 121:3-10.

48. Laurent O, Pedrono G, Segala C, Filleul L, Havard S, Deguen S, Schillinger C, Rivière E, Bard D: Air pollution, asthma attacks, and socioeconomic deprivation: a small-area case-crossover study. Am J Epidemiol 2008, 168:58-65.

49. Ponce de Leon A, Anderson HR, Bland JM, Strachan DP, Bower J: Effects of air pollution on daily hospital admissions for respiratory disease in London between 1987-88 and 1991-92. J Epidemiol Community Health 1996, 50(Suppl 1):s63-s70.

50. Atkinson RW, Bremner SA, Anderson HR, Strachan DP, Bland JM, de Leon AP: Short-term associations between emergency hospital admissions for respiratory and cardiovascular disease and outdoor air pollution in London. Arch Environ Health 1999, 54:398-411.

51. Carracedo-Martínez E, Taracido M, Tobias A, Saez M, Figueiras A: Casecrossover analysis of air pollution health effects: a systematic review of methodology and application. Environ Health Perspect 2010, 118:1173-1182

52. Marshall JD, Brauer M, Frank LD: Healthy neighborhoods: walkability and air pollution. Environ Health Perspect 2009, 117:1752-1759.

53. Rundell KW, Caviston R, Hollenbach AM, Murphy K: Vehicular air pollution, playgrounds, and youth athletic fields. Inhal Toxicol 2006, 18:541-547.

54. Clougherty JE: A growing role for gender analysis in air pollution epidemiology. Environ Health Perspect 2010, 118:167-176.

55. Prisby RD, Muller-Delp J, Delp MD, Nurkiewicz TR: Age, gender, and hormonal status modulate the vascular toxicity of the diesel exhaust extract phenanthraquinone. J Toxicol Environ Health A 2008, 71:464-470.

56. Hermes GL, Rosenthal L, Montag A, McClintock MK: Social isolation and the inflammatory response: sex differences in the enduring effects of a prior stressor. Am J Physiol Regul Integr Comp Physiol 2006, 290:R273-282. 
57. Sood A, Cui X, Qualls C, Beckett WS, Gross MD, Steffes MW, Smith LJ, Jacobs DR Jr: Association between asthma and serum adiponectin concentration in women. Thorax 2008, 63:877-882.

58. Mitsakou C, Housiadas C, Eleftheriadis K, Vratolis S, Helmis C,

Asimakopoulos D: Lung deposition of fine and ultrafine particles outdoors and indoors during a cooking event and a no activity period. Indoor Air 2007, 17:143-152.

59. Kim CS, Hu SC: Total respiratory tract deposition of fine micrometer-sized particles in healthy adults: empirical equations for sex and breathing pattern. J Appl Physiol 2006, 101:401-412.

doi:10.1186/1476-069X-10-31

Cite this article as: Tramuto et al: Urban air pollution and emergency room admissions for respiratory symptoms: a case-crossover study in

Palermo, Italy. Environmental Health 2011 10:31.

Submit your next manuscript to BioMed Central and take full advantage of:

- Convenient online submission

- Thorough peer review

- No space constraints or color figure charges

- Immediate publication on acceptance

- Inclusion in PubMed, CAS, Scopus and Google Scholar

- Research which is freely available for redistribution

Submit your manuscript at www.biomedcentral.com/submit 